\title{
Aplikasi Pemodelan Gedung Rektorat Universitas Udayana Berbasis Virtual Reality
}

\author{
Made Bagus Winanda Radityatama, Gusti Made Arya Sasmita, Ni Kadek Ayu Wirdiani \\ Program Studi Teknologi Informasi, Fakultas Teknik, Universitas Udayana \\ e-mail: radit4571@gmail.com, aryasasmita88@gmail.com, ayu wirdi@yahoo.com
}

\begin{abstract}
Abstrak
Gedung Rektorat Universitas Udayana merupakan pusat kegiatan akademik administrasi Universitas Udayana yang terletak di Bukit Jimbaran, Kabupaten Badung, Provinsi Bali, yang berfungsi sebagai pusat kegiatan akademik administrasi Universitas Udayana. Gedung Rektorat dipergunakan sebagai kantor Rektor, Wakil Rektor I (Bidang Akademik), Wakil Rektor II (Bidang Administrasi Umum dan Keuangan), Wakil Rektor III (Bidang Kemahasiswaaan dan Alumni), dan Wakil Rektor IV (Bidang Perencanaan, Kerjasama, dan Teknologi Informasi dan Komunikasi). Aplikasi Pemodelan Gedung Rektorat Universitas Udayana berbasis Virtual Reality dikembangkan pada penelitian ini sebagai media pendukung promosi Universitas Udayana. Aplikasi diimplementasikan berbasis Virtual Reality dengan model interior yang menyerupai keadaan nyata dan memiliki fitur deskripsi tentang beberapa ruangan disertai dengan suara. Pembuatan Aplikasi Pemodelan Gedung Rektorat Universitas Udayana berbasis Virtual Reality menggunakan Software SketchUp untuk proses pembuatan tiga dimensi gedung dan Software Unity untuk penyempurnaan pembuatan virtual reality. Hasil pengujian aspek kegunaan aplikasi yang diujikan kepada responden mahasiswa yaitu $80 \%$ respon positif dan hasil pengujian aspek kegunaan aplikasi yang diujikan kepada responden masyarakat yaitu $89 \%$ respon positif.
\end{abstract}

Kata kunci: Virtual Reality, Gedung Rektorat Universitas Udayana, Software SketchUp, Software Unity

\begin{abstract}
The Udayana University Rector Building is the center of the administrative academic activities of Udayana University located in Bukit Jimbaran, Badung Regency, Bali Province, which functions as the center of the academic activities of Udayana University administration. The Rector Building is used as the office of the Chancellor, Deputy Chancellor I (Academic Affairs), Deputy Chancellor II (General and Financial Administration), Deputy Chancellor III (Student and Alumni Field), and Vice Chancellor IV (Planning, Cooperation and Information Technology) and Communication). The Modeling Application of the Udayana University Rectorate Building based on Virtual Reality was developed in this study as a promotional support media for Udayana University. The advantages of the Modeling Application of the Udayana University Rector Building based on Virtual Reality are interior models that are almost similar to the real conditions of the Udayana University Rectorate Building and feature a description of several rooms in each floor of the Udayana University rector's building accompanied by voices. Making the Modeling Application of the Udayana University Rector Building based on Virtual Reality uses SketchUp Software for the process of making three dimensions of the Udayana University rectorate building and Unity Software for improving the making of virtual reality. The results of testing the usefulness aspects of the application that were tested on student respondents was $80 \%$ positive response, the results of testing the usefulness aspects of the application tested to community respondents were $89 \%$ positive responses.
\end{abstract}

Keywords: Virtual Reality, Udayana University Rectorate Building, SketchUp Software, Unity Software

\section{Pendahuluan}

Aplikasi Pemodelan Gedung Rektorat Universitas Udayana Berbasis Virtual Reality 
Gedung Rektorat Universitas Udayana merupakan pusat kegiatan akademik administrasi Universitas Udayana yang terletak di Bukit Jimbaran, Kabupaten Badung, Provinsi Bali, yang berfungsi sebagai pusat kegiatan akademik administrasi Universitas Udayana. Gedung Rektorat dipergunakan sebagai kantor Rektor, Wakil Rektor I (Bidang Akademik), Wakil Rektor II (Bidang Administrasi Umum dan Keuangan), Wakil Rektor III (Bidang Kemahasiswaaan dan Alumni), dan Wakil Rektor IV (Bidang Perencanaan, Kerjasama, dan Teknologi Informasi dan Komunikasi). Berbagai macam ruangan terdapat pada Gedung Rektorat Universitas Udayana yang terdiri dari 3 lantai, seperti ruang perkuliahan, laboratorium komputer, aula dan perpustakaan.

Aplikasi Pemodelan Gedung Rektorat Universitas Udayana berbasis Virtual Reality dikembangkan pada penelitian ini sebagai media promosi. Aplikasi dirancang mampu menggambarkan Gedung Rektorat Universitas Udayana dengan model bangunan dan ruangan yang menyerupai aslinya serta berisi deskripsi tentang beberapa ruangan yang ada di Gedung Rektorat Universitas Udayana.

Aplikasi Virtual Reality telah dikembangkan pada beberapa penelitian untuk media pembelajaran yaitu Aplikasi Media Pembelajaran sistem tata surya dengan virtual reality [1], pembelajaran mengenai pengenalan Dewata Nawa Sanga [2], pembelajaran IImu Pengetahuan Sosial dalam permainan edukasi dengan konsep labirin [3]. Aplikasi Virtual Reality sistem tata surya merupakan aplikasi pembelajaran yang memungkinkan pengguna berinteraksi dengan keberadaan planet-planet dari sistem tata surya secara virtual serta berisi informasi di dalamnya. Aplikasi pembelajaran pengenalan Dewata Nawa Sanga adalah aplikasi yang membantu proses pendidikan dengan informasi Dewa-dewa penjaga sembilan arah mata angin. Aplikasi pembelajaran Ilmu Pengetahuan Sosial dengan konsep labirin menggunakan Metode Collision Detection dan Penglihatan Stereoscopic pada SDK GoogleVR.

Beberapa penelitian yang telah berhasil menerapkan VR untuk media pembelajaran dengan visualisasi 3 dimensi menjadi dasar pembuatan Aplikasi Pemodelan Gedung Rektorat Universitas Udayana berbasis Virtual Reality. Aplikasi Pemodelan Gedung Rektorat Universitas Udayana memanfaatkan Software SketchUp dan Software Unity. Software SketchUp untuk proses pembuatan tiga dimensi gedung. Software Unity untuk penyempurnaan pembuatan virtual reality.

\section{Metodologi Penelitian}

Data yang dibutuhkan perangkat lunak untuk diproses, sehingga mendapatkan hasil yang diinginkan. Data merupakan informasi awal yang digunakan sebagai penunjang studi kasus yang berhubungan dengan perancangan dan pembuatan aplikasi Virtual Reality. Hal yang dijelaskan mengenai data antara lain yaitu sumber data dan metode dari pengumpulan data yang dilakukan.

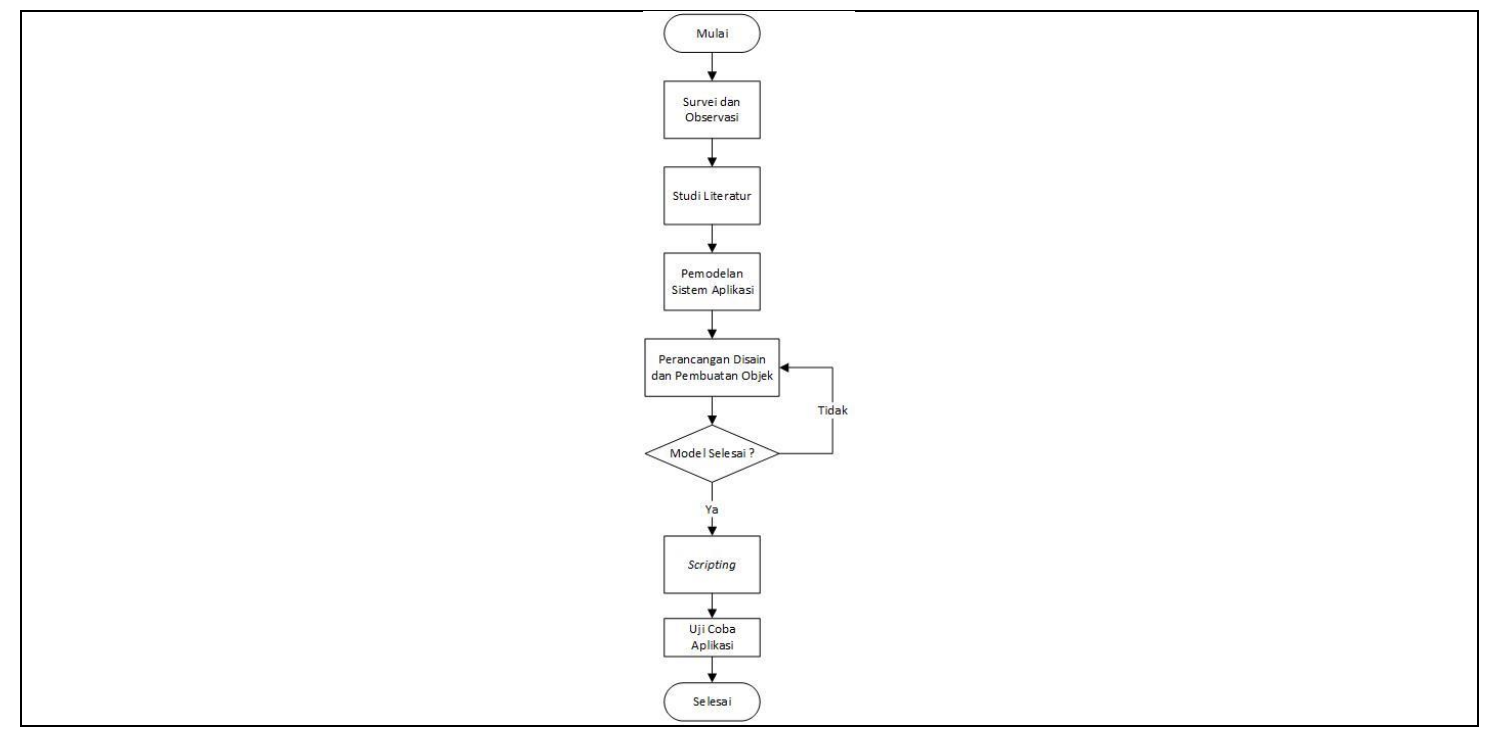

Gambar 1. Flowchart Metode Pelaksanaan 
Gambar 1. Merupakan langkah-langkah metode pelaksanaan pada pembuatan Aplikasi Pemodelan Gedung Rektorat Universitas Udayana Berbasis Virtual Reality.

\subsection{Survei dan Observasi}

Survei dan Observasi dalam menganalisis dan melakukan wawancara dan pencatatan terhadap salah satu staff yang bekerja di Gedung Rektorat Universitas Udayana serta melihat seluruh isi ruangan Gedung Rektora. Proses tersebut untuk menyesuaikan informasi dan model dari Gedung Rektorat dengan aplikasi yang dibuat.

\section{$2.2 \quad$ Studi Literatur}

Studi literatur merupakan pengumpulan data informasi dengan cara mencari sumbersumber seperti buku, karya tulis, jurnal, internet, dan sumber lain yang berhubungan dengan objek penelitian.

\subsection{Pemodelan Sistem Aplikasi}

Pemodelan sistem merupakan suatu sistem berupa gambaran seperti diagram alir dari suatu data pada umumnya yang sering digunakan yaitu gambaran umum sistem, use case, maupun jenis pemodelan sistem lain.

\subsection{Perancangan Disain dan Pembuatan Objek}

Perancangan desain dan pembuatan objek dilakukan dalam aplikasi Sketchup untuk pemodelan 3 dimensi Gedung Rektorat yang kemudia di export ke aplikasi Unity untuk pembuatan Virtual Reality.

\subsection{Scripting}

Scripting adalah semacam metoda membuat kode program atau menulis skrip pada text editor. Kode program yang dibuat digunakan sebagai kinerjanya aplikasi sehingga aplikasi dapat dijalankan.

\subsection{Uji Coba Aplikasi}

Uji Coba dilakukan untuk mengetahui kinerja aplikasi seberapa jauh aplikasi tersebut berjalan. Hasil dari pengujian akan menjadi evaluasi bagi aplikasi yang dikembangkan.

\subsection{Gambaran Umum Aplikasi}

Gambaran umum ini merupakan desain perangkat keras dan juga perangkat lunak yang baik. Perangkat keras yang digunakan yaitu Google Cardboard. Google Cardboard merupakan perangkat pendukung untuk penggunaan aplikasi Virtual Reality. Gambaran umum sistem ditampilkan sebagai berikut. 


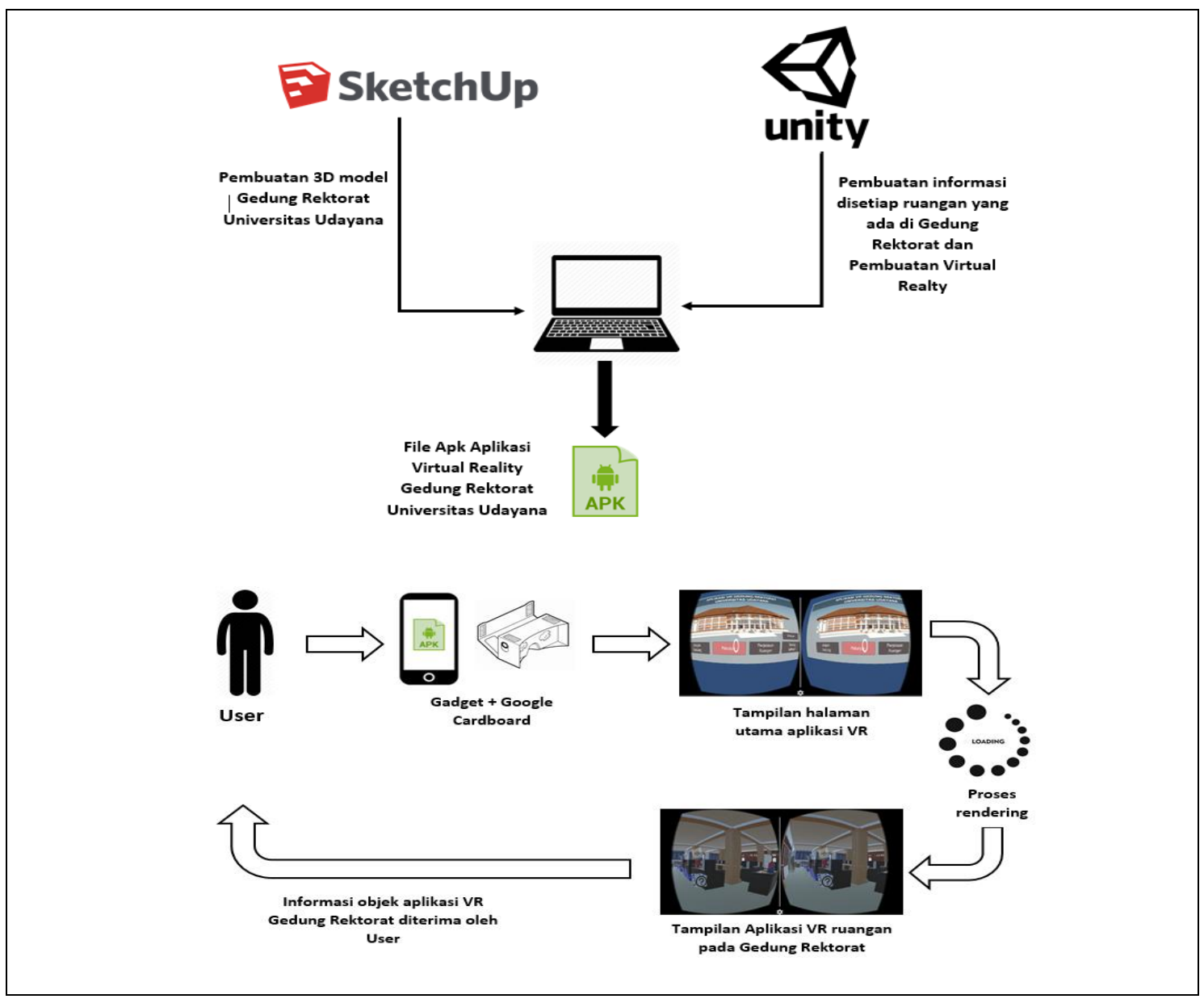

Gambar 2. Gambaran Umum Aplikasi

Gambar 2.1 menunjukan aplikasi Sketchup digunakan untuk membuat 3D modeling bangunan Gedung Rektorat Universitas Udayana dan aplikasi Unity untuk pembuatan informasi setiap ruangan yang ada pada Gedung Rektorat serta penyempurnaan pembuatan virtual reality lalu setelah file apk sudah jadi, user menggunakan google cardboard yang sudah dipasangkan gadget dengan aplikasi Virutal Reality Gedung Rektorat Universitas Udayana menampilkan informasi objek dari aplikasi tersebut.

\section{Kajian Pustaka}

Kajian pustaka merupakan materi referensi dalam pembuatan penelitian. Referensi berikut mengenai penjelasan Virtual Reality, Sketchup, Unity3D Game Engine, dan ruangan yang ada pada Gedung Rektorat Universitas Udayana dari lantai 1, lantai 2 dan lantai 3.

\subsection{Virtual Reality}

Virtual Reality adalah pemanfaatan teknologi komputer untuk menciptakan efek interaktif dunia 3D yang tiap objeknya dapat berinteraksi, berbeda dengan teknologi 3D konvensional yang hanya menggambarkan objek. Interaksi adalah karakteristik penting dalam lingkungan virtual dan sangat kompleks. Pengguna harus mampu menavigasi ruang 3D, memanipulasi objek virtual atau parameter kontrol dari simulasi dan berinteraksi dengan GUI 3D yang berada di lingkungan virtual [4].

Ide mengenai Virtual Reality dipresentasikan pertama kali oleh Ivan Sutherland pada Tahun 1965 dengan tujuan untuk membuat dunia virtual di jendela terlihat nyata, terdengar nyata, terasa nyata, dan menanggapi respons pengguna secara nyata [5]. 


\subsection{SketcUp}

Sketchup salah satu software yang mempunyai fungsi dalam desain grafis dengan model 3 dimensi yang digunakan dan dirancang untuk para profesional di bidang teknik sipil, arsitektur, dalam pembuatan game, film, dan rancangan yang terkait didalamnya. Pemanfaatan Sketch-Up membantu kemampuan siswa dalam memvisualisasikan ruang [6].

\subsection{Unity3D Game Engine}

Unity3D Game Engine adalah tool pengembangan terintegrasi untuk mengembangkan konten interaktif seperti video games, visualisasi arsitektur dan animasi 3D. Unity3D Game Engine berjalan pada Windows OS dan Mac OS X, namun memiliki kemampuan untuk mengembangkan aplikasi multiplatform seperti Windows, Windows Phone, Mac OS X, iOS, Wii, Linux, Android, dan Web Player dengan memanfaatkan Software Depelopment Kit (SDK) terkait [7].

\subsection{Lantai 1}

Lantai 1 memiliki tiga ruangan yaitu bagian barat ruangan Biro Administrasi Akademik Kerjasama dan Kehumasan, ruangan ini memiliki bagian Akademik serta bagian Kerjasama dan Humas yang menjadi satu ruangan, bagian timur ruangan Barang Milik Negara (BMN), ruangan ini memiliki bagian Perlengkapan dan Bagian Sumber Daya Manusia (SDM) yang dibagi menjadi dua ruangan.

\subsection{Lantai 2}

Lantai 2 bagian utara ada ruangan Rektor, bagian timur memiliki ruangan Tata Usaha dan Hukum Tata Laksana, bagian barat memiliki ruangan Lembaga Pengembangan, Pembelajara, dan Penjaminan Mutu (LP3M), bagian selatan ruangan WR IV dan One Health Colab Center (OHCC).

\subsection{Lantai 3}

Lantai 3 bagian utara memiliki ruang Bangsa, bagian timur memiliki ruangan Biro Perencanaan Keuangan Unud (BPKU) dan ruangan Biro Kemahasiswaan (BKM), bagian barat memiliki ruang Nusa, bagian selatan memiliki ruangan Arsiparis.

\section{Hasil dan Pembahasan}

Penelitian beikut membahas tentang Aplikasi Pemodelan Gedung Rektorat Universitas Udayana Berbasis Virtual Reality. Aplikasi ini menggunakan platform android dengan spesifikasi minimum processor $2.3 \mathrm{GHz}$ quad-corelntel Atom Z3580, RAM 3 gigabyte. Aplikasi VR ini memerlukan sensor gyroscope untuk menjalakan aplikasi pada gadget.

\subsection{Scene Menu Utama}

Scene menu utama merupakan scene awal aplikasi Virtual Reality Gedung Rektorat Universitas Udayana, yang berisi button Jelajah Gedung, button Petunjuk, button Penjelasan Ruangan, button Tentang Aplikasi, dan button Keluar.

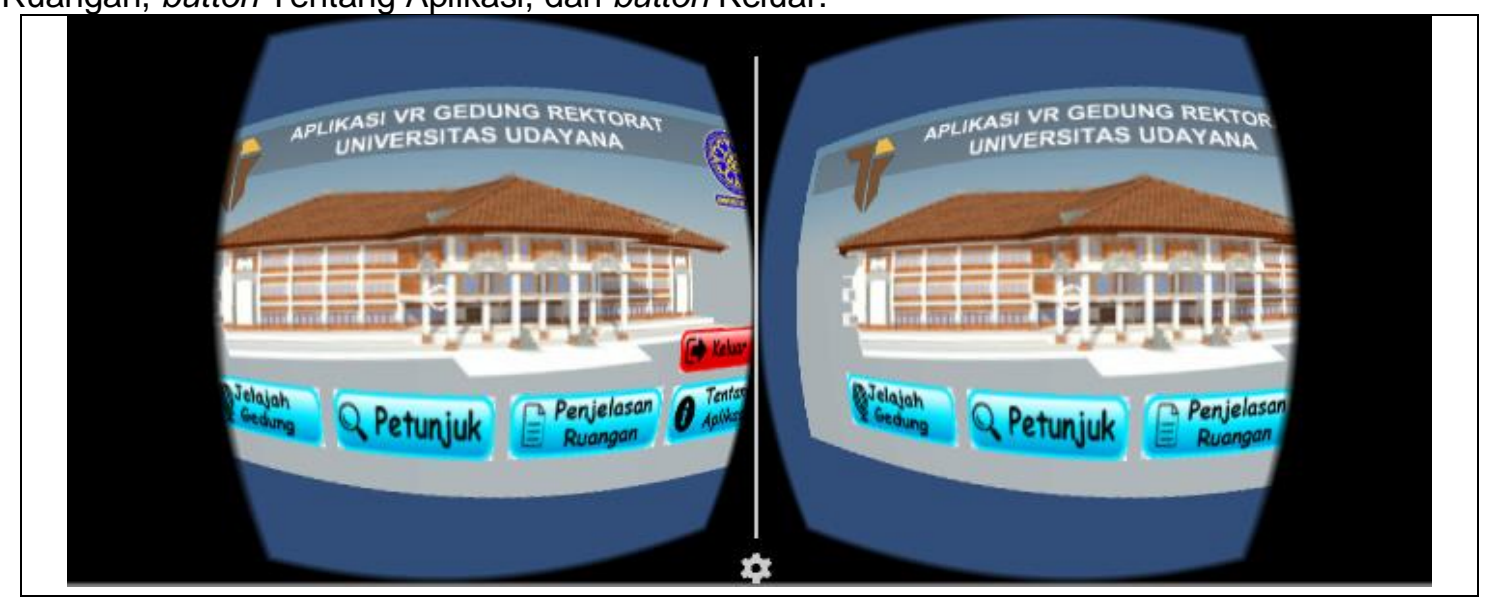

Gambar 3 Tampilan Menu Utama 
Gambar 3 merupakan tampilan scene uji coba menu utama yang berisi menu Jelajah Gedung untuk memulai jelajah seluruh isi ruangan Gedung Rektorat dari lantai 1, lantai 2, sampai lantai 3, selanjutnya menu Petunjuk memberikan informasi petunjuk-petunjuk menggunakan aplikasi virtual reality tersebut, menu Penjelasan ruangan berisi nama-nama ruangan serta informasi ruangan, menu Tentang Aplikasi berisi nama pembuat aplikasi, dan menu Keluar untuk menutup aplikasi.

\subsection{Scene Lantai 1}

Scene lantai 1 merupakan scene yang berisi model bangunan Gedung Rektorat pada lantai 1 memiliki beberapa ruangan yaitu bagian barat ruangan Biro Administrasi Akademik Kerjasama dan Kehumasan, ruangan ini memiliki bagian Akademik serta bagian Kerjasama dan Humas yang menjadi satu ruangan, bagian timur ruangan Barang Milik Negara (BMN), ruangan ini memiliki bagian Perlengkapan dan Bagian Sumber Daya Manusia (SDM) yang dibagi menjadi dua ruangan.

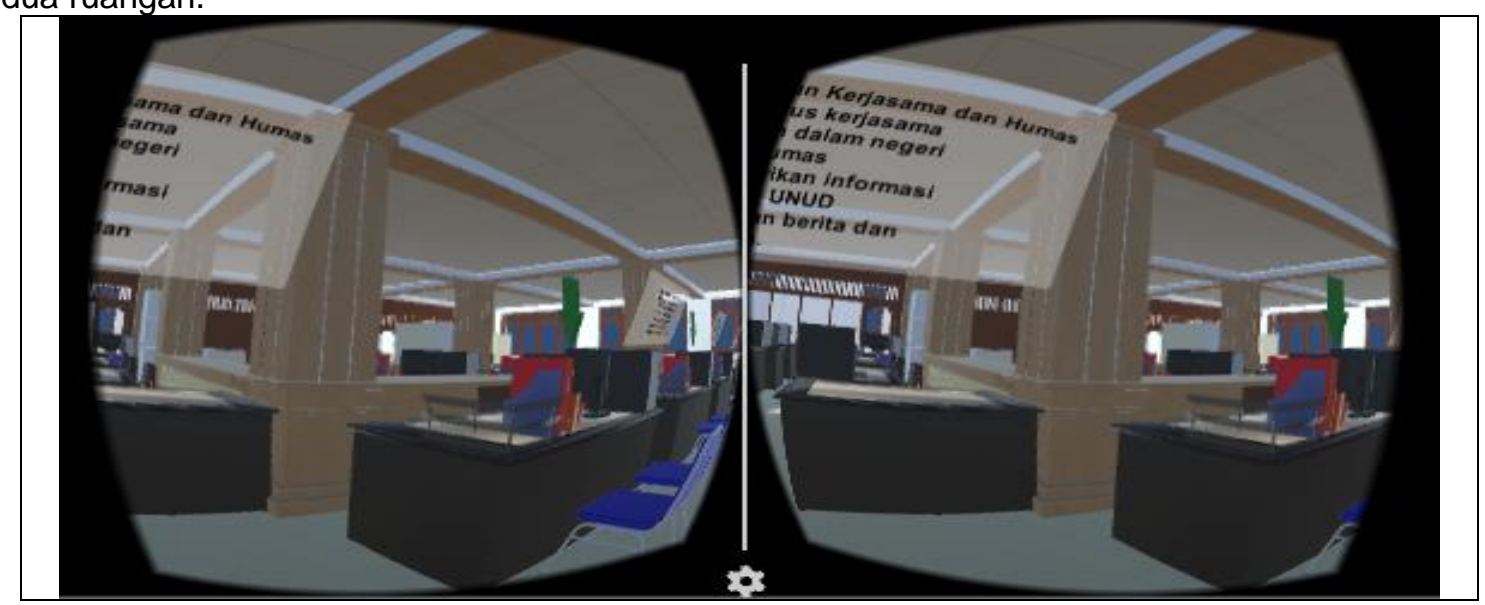

Gambar 4 Tampilan Scene Lantai 1

Gambar 4 merupakan tampilan Scene lantai 1 model Gedung Rektorat Universitas Udayana yang berisi informasi-informasi ruangan.

\subsection{Scene Lantai 2}

Scene lantai 2 merupakan scene yang berisi model bangunan Gedung Rektorat pada lantai 2 memiliki beberapa ruangan yaitu bagian utara ada ruangan Rektor, bagian timur memiliki ruangan Tata Usaha dan Hukum Tata Laksana, bagian barat memiliki ruangan Lembaga Pengembangan, Pembelajara, dan Penjaminan Mutu (LP3M), bagian selatan ruangan WR IV dan One Health Colab Center (OHCC).

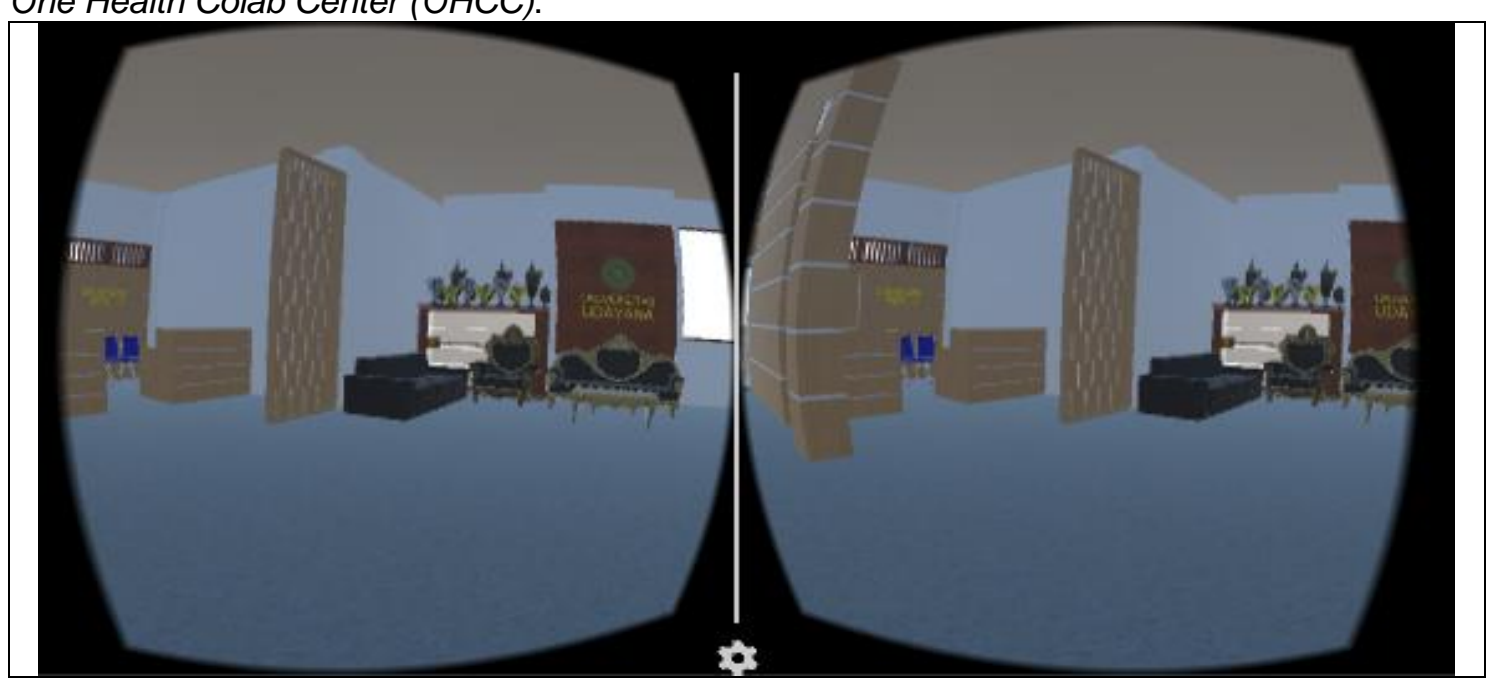

Aplikasi Pemodelan Gedung Rektorat Universitas Udayana Berbasis Virtual Reality 
Gambar 5 Tampilan Scene Lantai 2

Gambar 5 merupakan tampilan Scene lantai 2 model Gedung Rektorat Universitas Udayana yang berisi informasi-informasi ruangan.

\subsection{Scene Lantai 3}

Scene lantai 3 merupakan scene yang berisi model bangunan Gedung Rektorat pada lantai 3 memiliki beberapa ruangan yaitu bagian utara memiliki ruang Bangsa, bagian timur memiliki ruangan Biro Perencanaan Keuangan Unud (BPKU) dan ruangan Biro Kemahasiswaan (BKM), bagian barat memiliki ruang Nusa, bagian selatan memiliki ruangan Arsiparis.

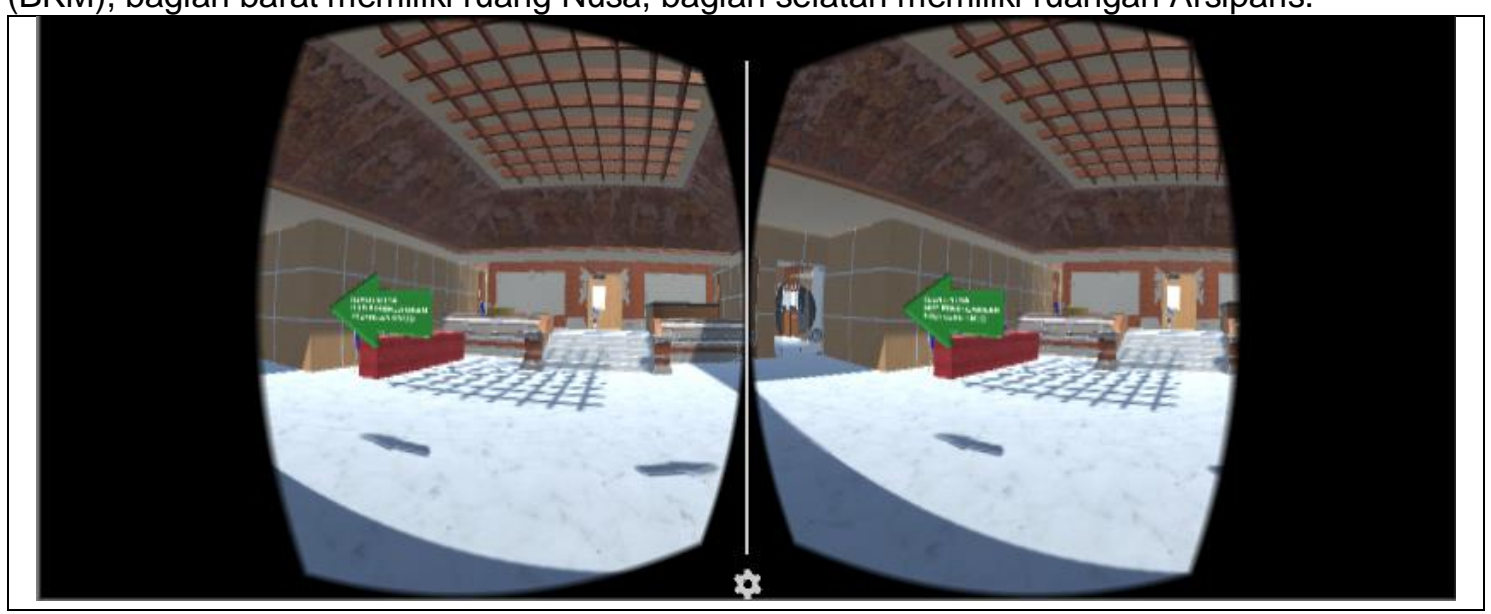

Gambar 6 Tampilan Scene Lantai 3

Gambar 6 merupakan tampilan Scene lantai 3 model Gedung Rektorat Universitas Udayana yang berisi informasi-informasi ruangan

\section{Kesimpulan}

Kesimpulan dari pengujian Aplikasi Pemodelan Gedung Rektorat Universitas Udayana berbasis Virtual Reality yaitu mampu memberikan informasi secara interaktif yang mendukung fungsi aplikasi sebagai media pendukung promosi institusi. Kelebihan Aplikasi Pemodelan Gedung Rektorat Universitas Udayana berbasis Virtual Reality yaitu model interior yang hampir mirip dengan keadaan nyata pada Gedung Rektorat Universitas Udayana dan memiliki fitur menampilkan deskripsi tentang beberapa ruangan yang ada disetiap lantai Gedung Rektorat Universitas Udayana disertai dengan suara. Hasil pengujian aspek kegunaan aplikasi yang diujikan kepada responden mahasiswa menunjukkan $80 \%$ respon positif, hasil pengujian aspek kegunaan aplikasi yang diujikan kepada responden masyarakat menunjukkan $89 \%$ respon positif.

\section{Daftar Pustaka.}

[1] I. M. S. R. I Putu Astya Prayudha, A.A. Kt. Agung Cahyawan Wiranatha, "Aplikasi Virtual Reality Media Pembelajaran Sistem Tata Surya," MERPATI, vol. 5, no. 2, pp. 72-80, 2011.

[2] N. N. W. Rudiasti, A. A. K. Sudana, and M. S. Raharja, "Android based Introduction of Dewata Nawa Sanga Virtual Reality Application,” Int. J. Comput. Appl., vol. 169, no. 7, pp. 38-45, 2017.

[3] S. G. A. Bhaskara, "Permainan Edukasi Labirin Virtual Reality Dengan Metode Collision Detection Dan Stereoscopic," Lontar Komput., vol. Volume 8, no. Nomor 2, p. Halaman 65-76, 2017.

[4] F. Popovski, I. Nedelkovski, and S. Mijakovska, "Generating 3D Model in Virtual Reality and Analyzing Its Performance," Int. J. Comput. Sci. Inf. Technol., vol. 6, no. 6, pp. 123128, 2014.

[5] S. Mandal, "Brief Introduction of Virtual Reality \& its Challenges," Int. J. Sci. Eng. Res., vol. 2006, no. 4, pp. 304-309, 2006.

[6] M. Duwain Brazley, "Architecture, Virtual Reality, Spatial Visualization, Learning Styles,

Aplikasi Pemodelan Gedung Rektorat Universitas Udayana Berbasis Virtual Reality 65 (Made Bagus Winanda Radityatama) 
and Distance Education," Int. J. Archit. Arts Appl., vol. 4, no. 2, p. 10, 2018.

[7] P. P. Patil and R. Alvares, "Cross-platform Application Development using Unity Game Engine," Int. J. Adv. Res. Comput. Sci. Manag. Stud., vol. 3, no. 4, pp. 1-9, 2015.

[8] DEWI, D. A. S., PUTRA, I. K. G. D. \& BAYUPATI, I. P. A, "Aplikasi Augmented Reality Jurusan Teknologi Informasi Universitas Udayana (AR-TI)," MERPATI, Vol. 5, No. 8, April 2017.

[9] I Gede Aditya Nugraha, I Ketut Gede Darma Putra, I Made Sukarsa,"Rancang Bangun Aplikasi Android AR Museum Bali : Gedung Karangasem dan Gedung Tabanan," Lontar Komputer, Vol. 7, No. 2, Agustus 2018.

[10] I Wayan Andis Indrawan, I Putu Agung Bayupati, Desy Purnami Singgih Putri," Markerless Augmented Reality Utilizing Gyroscope to Demonstrate the Position of Dewata Nawa Sanga,"IJIM, Vol. 12, No. 1, 2017. 